\title{
1. Spatial mobility, automation, and autonomy
}

'One of late modernity's most recognised and contested objects is the automobile' (Beckmann 2001, 593), 'often viewed as the avatar of mobility' (Thrift 1996, 272). The world of mobility is about to reach a crossroad, maybe its most dramatic one since the no less dramatic two previous ones. In the center of this upcoming crossroad stand proudly the autonomous vehicles. The first of the previous dramatic crossroads was the wide adoption of private automobiles (in the 1920s in the US and in the 1960s in Western Europe), and the second one was the later wide adoption of the Internet and the mobile phones (in the 1990s-2000s worldwide) (Kellerman 2006, 2012).

The upcoming introduction of autonomous vehicles (AVs), expected in the 2020s, and their possible later wide adoption, sometime during the following decades (2020s-2040s), will amount to the reaching of a fantastic technological achievement of autonomously operating cars. AVs may further signify wide and rather significant changes in the patterns and forms of human mobility, as well as to its social and spatial dimensions. These transitions will not be restricted to physical mobility only, but they will touch upon virtual mobility as well, and in several ways. The autonomous cars will communicate with each other, and passengers will use communications prior to their rides for reserving on-demand urban transit. Passengers will further use communications in specific patterns while riding AVs.

Automation processes for the worlds of transportation and information transmission have been around for a long time already, actually since the mid-19th century. As we will see, automation processes for information transmission have emerged earlier and more extensively than for road transportation. Our contemporary mobility media include, however, side by side, automated telephones, the Internet, traffic lights, and autopilots. These automated mobility systems have turned into routine and rather obvious elements of our mobility world, at both the individual and the societal levels, affecting our daily lives, as well as our cities, mainly in developed countries (see Kellerman 2012, 2014). AVs will constitute, therefore, an ultimate phase of automation for a rather continuous and 
quite long process for the development, adoption, and use of automated mobilities.

\subsection{BOOK OBJECTIVES AND SCOPE}

This book will attempt to offer an initial joint interpretation for automation as disseminated and used in highly varied mobility systems. Therefore, it will draw together knowledge from numerous relevant fields in the social sciences, notably from psychology, transportation, communications, sociology, geography, and planning. As we will see in Chapter 2, automation and its adoption have been approached from social science perspectives so far, mainly with a focus on automation processes in manufacturing, rather than in mobility.

In the following chapters, we will attempt to outline and discuss an extensive variety of automated modes and means of mobility, as well as the numerous controls for the traffic that they produce. This framework of automation and autonomous operations in mobility is of importance by itself, since it may facilitate a comparative view of automation in mobility, both from historical and contemporary perspectives.

The discussions on automation in mobility media have these days some additional significance and importance, given the emerging AVs, which will be discussed in Chapters 6 and 7. The highlighting of automation in mobility in general may facilitate a wider understanding and interpretation of the current development efforts for AVs. Furthermore, the exposure of automation in mobility in general may turn out as helpful not only for their development, but for their possible future adoption, and for their wide-ranging social ramifications, as well.

The wide scope of automated mobilities that are currently in operation may constitute the context and early roots of the upcoming AV revolution. As such, the approach for the following chapters will not be merely historical, though the developments of the numerous automated mobilities will be presented. The discussions and interpretations offered in this book for the numerous expressions of automation in mobility will lean mainly on social science studies and concepts, rather than on those taken from engineering. Therefore, the approach will consist of a blend of historical, geographical, and social approaches and dimensions. The explorations presented will further be based on the accumulation of research so far, on contemporary trends, and on interpretations developed in this book.

AVs now constitute the core for research and development (R\&D) efforts within both the automobile and the information technology (IT) industries, and these efforts take place in a number of countries. AVs are 
scheduled for initial commercial marketing by the early to mid-2020s. It is, therefore, time now to highlight the very notion of automation and its significance for mobilities at large, exposing its expressions and uses by individuals, as well as by providers of transportation and communications services. Automation in transportation refers to all vehicle types, used for the moving of both people and cargo. Side by side with the key role of automation in contemporary transportation, automation constitutes a key factor for the current enormous transmission (or movement) of information, notably through the Internet. Information transmission constitutes a major and rather separate class of automated mobility (discussed in Chapter 5), but, as we will see, it simultaneously has a special importance for the development and operation of autonomous, IT-driven vehicles.

In the rest of this chapter, we will mainly focus on the major notions that are at the heart of this book: mobility and spatial mobility, automation, and autonomy, attempting to expose their definitions, social meanings, and modeling. These separate elaborations will be followed by an integrating discussion of automated mobility. The following chapters will aim at the presentation and discussion of numerous forms and levels of automation, pertaining to corporeal, cargo, and information mobilities, to the controlling of these mobilities, as well as to their urban and social implications. Hence, the topics of the following chapters will include: human automated and autonomous self-mobility (Chapter 2); automated traffic controls (Chapter 3); automated public transportation (Chapter 4); automated virtual mobility (Chapter 5); autonomous vehicles (Chapter 6 ); and the autonomously mobile city (Chapter 7). The last chapter will present summaries and concluding discussions (Chapter 8).

It is hoped that the following discussions will turn out useful for transportation and mobility students, scholars, and professionals, who have to cope these days with the notion of automation, vis-à-vis the development of AVs. The notion of automation in mobility and transportation studies seems to have been neglected so far, or, alternatively, has been taken for granted, and left without proper interpretation. However, automation in mobility is there anywhere within contemporary transportation and communications systems worldwide, with ranging levels of adoption by developed and developing countries. Thus, for example, traffic light systems are installed and are operative in cities in all parts of the world, but they may function as independent systems for each road junction in poorer countries, whereas in richer countries they may operate centrally controlling and monitoring traffic light systems. Such centers are based on sensors and cameras installed in road junctions, so that the control centers may cover the control of city-wide and even metropolis-wide traffic light systems.

The joint discussion of automation for all the mobility modes offered 
in this book may bring about the identification of some common threads among these modes and their emergence, and these will be exposed mainly in the concluding chapter of the book (Chapter 8). Furthermore, this joint discussion of automation modes in mobility may shed some light on future landscapes of intelligent traffic within autonomously mobile cities, following wide AV adoption, and these will be highlighted in Chapter 7.

\subsection{SPATIAL MOBILITY}

Spatial mobility is the basic concept for this book, and the following discussion will attempt to define and assess it, based on Kellerman (2012). Spatial mobility constitutes the human natural ability to shift or move one's body across space, as well as the ability of humans to move their limbs in situ. Spatial mobility further constitutes the ability of humans to move themselves across space by using either ancient or contemporary mobility technologies. In addition, spatial mobility includes the human ability to move information, through its sending, retrieval, or arrival.

Specific spatial movements of one's body or one's information, using any transport vehicle or any communications device, involve a generally similar movement process. Thus, one's body or information is led by the vehicle or device, as was chosen by a user, from an origin (fixed or mobile), through some routes (e.g. roads, airlines, public transportation lines, telephone lines). Each movement is further managed en route through traffic controls (traffic lights, airport control centers, routers, exchanges, etc.), until the reaching of a predefined destination (fixed or mobile) (Figure 1.1) (see also Kellerman 2011). Beyond and beside these basic features of spatial mobility, it has been variously interpreted as displacement, as a meaningful condition, as an activity, and as an ability. Let us look separately at each of these four views.

The physical shifting of humans over space always involves displacement, whether it be minor and repetitive as, for instance, in daily commuting, or whether it be major and one way, such as in migration. Displacement constitutes the essence of spatial mobility, 'displacement of something across, over and through space' (Adey 2010, 13; see also Cresswell 2006a, 1-2; Morse 1998, 112). It is possible to view mobility as displacement for three sorts of movables: people, objects, and information/knowledge (Urry 2007, 7-8, 47; Kaufmann 2002), and these three movables may be differentiated by their mobility flexibility, using a state of matter metaphor (Kellerman 1993, 160). Moving information is as flexible as gas, easily changing modes, shapes, and volume, and its very transmission is instant. People's corporeal mobility may be viewed as similar to 


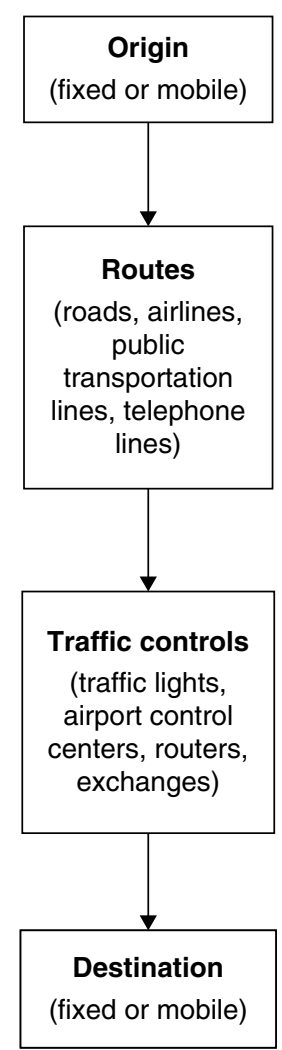

\section{Figure 1.1 General movement process}

liquid, exhibited through people's ability to change travel modes, as well as through their ability to be partially self-motored. Moving objects is the moving of solids, which by its very nature is slower, and always requires handling of the very moving of objects. All three movables are human in some way, since objects and information are sent by people and for people, and sometimes even replace human corporeal mobility.

Spatial mobility may eventually bring about some spatial and social changes, notably those that may emerge through cumulative movements of numerous individuals. From the perspective of the homo viator [mobile person] (Eyerman and Löfgren 1995), this displacement is practiced, experienced, and embodied in a variety of ways (Cresswell 2006a, 3). As such, spatial mobility is a meaningful condition, implying values such as progress, freedom, opportunity, and modernity (Cresswell 2006a: 1-2), as well as speed, when perceived as a condition and a value (Prato and 
Trivero 1985, 40; Virilio 1983, 45) and extensibility, again when viewed as a condition and value (Adams 1995; Kwan 2001).

Spatial mobility as displacement accentuates a condition. However, given the extensive and complex dimensions of spatial mobility, its study is not just interested in displacement and in shifts per se, but also in their contexts and significances. As such, the study of spatial mobility stretches beyond transportation geography (Shaw and Hesse 2010; Bissell et al. 2011). Any shift or mobility 'is given or inscribed with meaning. Furthermore, the way it is given meaning is dependent upon the context in which it occurs and who decides upon the significance it is given' (Adey 2010, 36). Spatial mobility as displacement has been viewed as a positive societal trend and force and as an integral part of the second modernity involving wide social implications (see e.g. Urry 2000, 2007). Spatial mobilities may further be differentiated along major demographic parameters, for instance gender (see e.g. Blumen and Kellerman 1990), age (see e.g. Burnett and Lucas 2010), and obviously along income.

Spatial mobility was also defined as an activity: 'geographical displacement, i.e. the movement of entities from an origin to a destination along a specific trajectory that can be described in terms of space and time' (Kaufmann 2004, 746). It was further defined as a social dimension: 'Spatial mobility is not an interstice, or a neutral liaison time between a point of origin and a destination. It is a structuring dimension of social life and of social integration' (Kaufmann 2002, 103; see also Urry 2000, 2007). In addition, spatial mobility was claimed to possess some hidden dimensions: 'mobility is polysemic and does not itself reveal what underlies it' (Kaufmann 2002, 101-3). Thus, for Baudrillard (1996, 66) 'effortless mobility entails a kind of pleasure that is unrealistic, a kind of suspension of existence, a kind of absence of responsibility'.

Another basic definition for spatial mobility, this time from the perspective of transportation geography, viewed mobility as an ability: 'Mobility refers to the ability to move between different activity sites' (Hanson 1995, 4). Similarly, movement was described as 'the idea of an act of displacement that allows objects, people, ideas - things - to get between locations' (Cresswell 2001, 14), whereas others provided a rather social and more restricted definition for mobility, as an actor's competence to realize certain projects and plans while being 'on the move' (Bonss and Kesselring 2004, 5).

The recent telecommunications/information revolution has emphasized the virtual dimension of the term spatial mobility, referring to the human ability to move a rather abstract entity, information, electronically over space, thus carrying out virtual spatial mobility. The growing significance of virtual mobility, and its integration with physical spatial 
mobility, which we will note later, mainly in Chapters 5-6, calls for some attention here. Electronically transmitted information may constitute a virtual extension of the self, through a phone call or through an email. Alternatively, it may constitute public pieces of information, available through websites, and as such it is not being transmitted as one-to-one messages or as one-to-many messages, oriented from one user to some specifically denoted receivers. Such website information constitutes rather on-demand retrieved information.

Urry (1999) referred to virtual information flows through the Internet as weightless traveling, whereas imaginative traveling refers to such flows through television broadcasts. Though television broadcasts amount to one-way public transmission of predetermined information, they were compared to the physical mobility of individuals via automobiles, claiming that 'television succeeded because it broadened and extended lifestyles associated with the motor-car; primarily those concerned with mobility as a shaping principle of communication' (Bachmair 1991, 522). Others called mobility vis-à-vis television the transport of the mind: 'Television turns out to be related to the motor car and the aeroplane as a means of transport of the mind' (Rudolf Arnheim, quoted in Morse 1998, 99).

The physical mobility of people has growingly involved, as of the 1970 s, virtual transfers of information, as well. For instance, information transmitted for travel booking and coordination, or for traffic control. Communications have become the key for the management of people's physical mobility. From yet another angle of joint physical and virtual mobilities, it has become possible for individuals to move corporeally while simultaneously communicating virtually through smartphones. Moreover, even the mobilities of people and objects are interrelated: 'There are objects that enable people to travel across distance; there are objects that enable people to travel forming complex hybrids. . . there are objects and people that move together' (Urry 2007, 50). The mass moving of objects has become increasingly organized and controllable through logistics and modal transportation. Individuals, on the other hand, tend, in many cases, to prefer individual mobility for their daily commuting, making use of personal mobility vehicles, i.e. cars, cycles, and bicycles.

Three possible relations may emerge between physical and virtual media for personal spatial mobility, assuming that virtual media for personal mobility, mainly the Internet and smartphones, are available for use by individuals, side by side with those for physical mobility (Kellerman 2014). The first type of relations is substitution, i.e. virtual mobility replacing people's physical movements, such as in the performance of banking actions through the Web instead of at the physical bank branch. As Janelle 
(2004, 86) noted: 'virtual mobility refers to the substitution of electronic transfers and exchanges for physical transport activities'.

The second type of relations between personal physical and virtual mobilities is complementarity, i.e. physical mobility becoming complemented by a virtual one, such as in phone calls performed in preparation for any physical movements. Finally, the third type of relations is additivity, which may emerge when a new movement for individuals is added through virtual mobility, such as in the addition, at the time, of general information search engines (e.g. Google and Bing), or the recently growing habit of calling over mobile phones while driving or riding cars (see Kellerman 2006, 2016).

Our following discussions of automated spatial mobilities, in this as well as in later chapters (notably Chapters 5-6), will refer to daily mobilities, such as for commuting, shopping, socializing, information searches, banking, news updating, studies, business meetings, etc. Several features typify these daily mobilities: they are two way; they are frequently performed; they constitute a major element of our daily routine lives, and they are inclusive of both corporeal and/or virtual mobilities. Following McKenzie (1927), Kaufmann (2009) suggested a distinction between daily movements, which he termed fluidity, and non-daily movements (mainly tourism and migration), which he called mobility. Fluidity was supposed by Kaufmann to have no effect on one's life, as compared to non-daily mobilities. However, repeated daily movements may involve significant impacts on one's life as a mobile person, in terms of the extent of people's activity space for activities other than commuting, as well as in terms of their accessibility and extensibility. The cumulative and repetitive daily movements by individuals may bring about, at least for some people, future non-daily movements of residential change, travel, and even migration. In general, Bán $(2007,289)$ suggested that 'with all of his or her everyday movement, Homo sapiens transformed into Homo mobilis'.

\subsection{AUTOMATION AND MOBILITY}

Automation is the major condition that we would like to examine in this book, in lieu of the availability and performance of spatial mobility, as the basic concept discussed. The terms automatic and automation stem from the Greek automatos [ $\alpha$ vó $\mu \alpha \tau o \zeta]$, which means self-doing. Thus, automatic, as a process, was defined as 'working by itself with little or no direct human control', and automation was defined accordingly as 'the use or introduction of automatic equipment in a manufacturing or other process or facility' (Oxford Living Dictionaries 2016). The use of the term 
automatic dates back to the mid-18th century, whereas its noun automation was introduced much later, in the US in 1946 (Pursell 1995, 287), and considered linguistically as an 'irregular formation from automatic' (Oxford Living Dictionaries 2016).

From a human perspective, automation was defined 'as the execution by a machine agent (usually a computer) of a function that was previously carried out by a human. What is considered automation will therefore change with time' (Parasuraman and Riley 1997, 231). However, the contemporary widely extending use of computer power has also brought about automatic processes that have been automatic from their very outset, for things that humans could only have carried out such processes manually. The Internet and numerous smartphone apps are leading examples in this regard, since they have never constituted manual systems turned into automatic ones. Automation, therefore, is not merely a type of mechanical process replacing one or several manual processes, but it rather constitutes self-operating mechanisms that have become an integral element in people's operations, while humans still determine the timings for such automated operations. Thus, 'in modern times, humans are consumers of automation' (Parasuraman and Riley 1997, 231).

Put yet another way, automation referred until recently to the automation of industrial and service processes previously operated manually by professional workers. The recent massive computerization of daily activities, notably through the Internet and smartphones, has turned automation into a consumer-end process, so that automation is widely felt by individuals in general, and not just by service operators or by industrial workers. This change is of special significance in the mobility arena. Thus, it has been for manual professional activities in the area of mobilitycontrol processes (such as car and train traffic control), which will be discussed in Chapter 3, to become automated. Such automation of previously manually operated systems applies also to the driving/operation of public transportation media, to be discussed in Chapter 4. For personal mobility, on the other hand, as we will note in Chapters 5-6, fixed line telephone services were automated early on in their development, whereas the Internet and mobile phone services have been automatic from their outset. Human-driven cars, used for physical personal mobility, will be the last mobility mode to undergo a revolutionary full automation process, eventually effective to all drivers, non-professional and professional alike.

Automation does not reduce the human dominance over production or service activities and processes; on the contrary, automation may increase human dominance over complex and multi-phase production and service activities, even when they have turned into fully autonomous processes, without any seemingly human intervention, for their performance. This 
human predominance is there because human beings still keep the major, and rather crucial, dimensions of dominance: the determination of the purpose of production, which in mobility implies the determination of movement destinations, the exclusive ability of humans to direct process activation (and stopping if not automatically pursued at destination), and the determination of operation timing by humans.

It is for automation to take care of the middle phase between the determination of process objectives and their activation, made by humans before their starting, and the reaching of the determined purpose and process stopping, which may be either automatic or manual. This middle phase is the production/operation phase, which may involve much effort if manually carried out. Automation further enhances human domination over time resources, in its freeing of individuals' time, which was previously used for production, for the performance of any other activities. Automation may reduce labor costs, side by side with the facilitation of increased production volumes, and this might have been the trigger for its popularity in the capitalist US economy. This latter reduction of labor costs may, potentially at least, imply a heavy social toll, through a possible emergence of unemployment among workers who performed production or service activities before their transformation into automated ones. However, the prolonged adoptions of industrial automation processes have not been met with any major unrest stemming from workers' displacement (Simon 1981). This has mainly been the case because automation may bring about a reduced number of workers in a given production process, whereas simultaneously new workers may be needed for the handling of increased production volumes and their marketing and distribution.

The introduction of innovations and processes, being either automatic in nature or contributing to processes of automation, even though they were not named as such, dates back to early times in human history. The first automatic processes were documented for the Greek era. The history of automation has been presented and discussed elsewhere (see e.g. Bennett 1996; Bissell 2009), and is summarized in Table 1.1. The milestones for the development of automation technologies, as can be seen in the table, call for some general observations.

Automation, or processes and actions taking place without human intervention in their routine operation, require some energy sources for their operation and control, other than human energy. Thus, the earliest human attempts for automation, the Greek water clock and the Arab float regulators, were based on the power of running water. This energy source was used also in later periods. In Medieval Europe, the ability to store human energy through clock spring stretching was added to the use of 
Table 1.1 Milestones in the development of automation and autonomous operations technologies towards the introduction of $A V S$

Year/period
Ancient Greece
c. 270 B.C.
Ancient Arabia (Baghdad)
9th century
Medieval and post-Medieval Europe
1335
Middle Ages
17th-18th centuries
Industrial Revolution
18th century
Late 18th century
1801

19 th century

Mid-19th century

1866

20th century

1907-1914

1920s

1922

1932

1942-3

1946

$1950 \mathrm{~s}$

1964

1960s

1970 s

1980s

1984

1990

21 st century

2000s-2010s
Innovation/newness

Water clock

Float regulators

Mechanical clock

Automatic sail turning for windmills

Incubator temperature control

Steam engine

Steam engine control

Complex textile pattern production by

automatic looms

Electricity

Feedback in ship steering engines

Automatic block signaling for trains

\begin{abstract}
Autopilots
Controlling electronic circuits through feedbacks

Automatic traffic lights

Hydraulic automatic transmission

Block diagrams for military applications

Computers

Sensors

Internet

Integrated circuits

Routers

Artificial intelligence

Autonomous traffic control center

GPS for car navigation

Integration of computers, sensors, artificial intelligence, and communications technologies for AVs
\end{abstract}

Source: Bennett 1996; Bissell 2009; McShane 1999; OTA 1976; LADOT 2012. 
water as an energy source, thus permitting automatic operation of clocks for several hours or days.

The Industrial Revolution brought about the use of engines powered by steam water. It became further possible for people to control these steam engines, hence, permitting their use for sailing and for trains, as well as for industrial production. The late 19th century and the early 20 th century witnessed the harnessing and production of electric energy, which has permitted since then an enormously wide variety of automatic processes, notably in production, telecommunications, and car driving. The second half of the 20th century brought about electronics-based innovations in information and communications technology, beginning with the computer, continuing with sensing, and culminating with artificial intelligence. The attempt in the 21 st century for the development of higher levels of automation, focusing on the introduction of AVs and robotics, does not imply the invention of new basic technologies per se. It rather involves the sophisticated and complex integration of information and communications technologies invented and developed in the 20th century (i.e. computers, sensors, artificial intelligence, and the Internet).

Automation for manufacturing, as well as for mobility systems, can be applied at numerous levels of automation (LoA). Frohm et al. (2008) reviewed several possible dimensions for LoA, as proposed by numerous scholars. First, human resources, via the degree of human replacement levels by automation, or the staffing level reduced by automation processes (Amber and Amber 1962; Groover 2001). Second, human-machine relations, via the feedback from machines to humans, or the amount of sharing between machines and humans (Sheridan 1980; Satchell 1998). Third, operational functions, as presented by technical levels related to specific work functions (Kern and Schumann 1985). Fourth, the automation spectrum, as expressed through the continuum from manual through automated to autonomous operations (Billings 1997; Parasuraman et al. 2000; Riley 1989).

As we will note later, LoA for mobility systems were proposed for only two specific mobility systems: metro automation, for which some four LoA were identified (Table 4.2), and AVs, for which some six LoA were proposed (Table 6.2). In both cases, the explicit and implicit dimensions for the categorization and leveling of mobility automation have been mixed, actually relating to all of the four generally proposed dimensions for LoA. Thus, the automation levels for metros and cars refer to the changing roles of drivers/operators; to the very necessity for operators/ drivers; to the specific operational systems of the vehicles becoming automated at any level; and, finally, to the identification of the several operation levels, being either manual, automatic, or autonomous. In the 
concluding chapter (Chapter 8), we will present LoA for spatial mobilities in general (Table 8.2), focusing on the extent of operational automation and the involvement of humans in their operations.

\subsection{AUTONOMOUS MOBILITY OPERATIONS}

A third major term for our explorations of automation in spatial mobility is autonomy (and autonomous), a term in use since the early 17 th century,

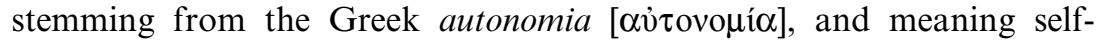
government. Thus, autonomy was defined, for non-governmental matters, as 'freedom from external control or influence' (Oxford Living Dictionaries 2016).

The term autonomous vehicles is a contemporary term, whereas the term 'automatic vehicle' dates back to the late 1930s, and refers to the automation of just a single mechanical system in car operations, namely the transmission system (to be discussed in Chapter 2). The contemporary term 'autonomous vehicle', rather, refers to autonomous vehicles, equipped with two automatic elements. First, automatic decision-making processes for driving actions for the whole duration of car trips, and second, a fully automatic operation of vehicles, replacing all manual activities and systems for car operation: ignition, driving, transmission, navigation, and above all the sensing of road conditions, in order to permit the safe fully automatic operation of a car.

Autonomous mobility operations may refer to both people and devices. Human autonomous mobility, as we will see in Chapter 2, involves freedom of choice as well as freedom of action. Autonomy for mobility machinery, as we will see in Chapters 3-6, presents autonomous operations for traffic control systems, for public transportation, for communications, and eventually also for private cars. The autonomous operations of these mechanized mobility means constitutes the ultimate level of automated functioning. Thus, autonomous operations of mobility means implies their provision of mobility at the service of people and authorities, and these human agents may still determine the timing and destinations for every specific movement, whereas autonomous mobility vehicles execute the driving and navigation without any human intervention.

The 21 st century is about to become the century of full autonomy as developed for automated mobility media, notably cars, as compared to the 20 th century, which was the century of automation for specific mechanical car systems. Though robots were introduced already during the second half of the 20th century, they were used mainly for specific phases in industrial production. In transportation, autopilots were introduced early in the 
20th century with human pilots monitoring their operations, and ready to intervene in case of trouble. In the 21st century, the ultimate objective of AV development is to introduce fully autonomous vehicles, guided and operated automatically, without any intervention by human drivers under any circumstances.

The wide introduction of automation and autonomous operations in mechanized mobility media, which we will see in the following chapters, may be related to the central role of speed in contemporary society, in addition to the push for economic efficiency and the human desire for automaticity. The speeding up of daily activities has reached all of our activities, whether for production or for social communication through the Internet. Much before the introduction of the commercial Internet, Virilio $(1983,45)$ called our era the age of the accelerator, and this nature of contemporary society has been accentuated time and again, notably regarding car driving, or accelerated personal physical mobility. 'Speed is the premier cultural icon of modern societies. . . Speed symbolizes manliness, progress, and dynamism' (Freund and Martin 1993, 89; see also Kellerman 2006).

\subsection{AUTOMATION, AUTONOMOUS MACHINES, AND UTOPIA}

Automation in general, and AVs in particular, have served as topics for utopian novels over the years (for a review see Kröger 2016). Our discussion here will rather focus on utopian approaches to autonomous machines, followed by utopian social views of societies based on automation and robotics.

For millennia, and culminating in Middle Ages Europe, people attempted to develop Perpeteuum Mobile, a kind of perpetual motion machine, which was supposed to operate continuously and endlessly without any external energy supply. The extensive intellectual and practical effort for the unrealistic possibility of developing such machines was truly a utopian one, and it testifies to a long-standing human yearning for automation, or for the development of mechanical operations free of human intervention.

Contemporarily, the continued development and adoption of sophisticated robots, mainly, but not only, for industrial production, as well as the potential future adoption of other autonomous systems, such as AVs, imply the possible assimilation of machines which will be able to work autonomously and continuously without human intervention. However, even these autonomous machinery systems will still consume energy, even though this consumption will be at lower levels than those required for internal combustion engines or hybrid cars. These developments seem 
like a contemporary and future realization of an ancient human dream for utopian perpetual motion machines. However, it should be noted that autonomous machines, such as robots and AVs, constitute human-made machines, so that the functionality and operations of these machines do not relate to the levels of personal autonomy of individuals in their mobility desires and actions (see Chapter 2 and Kellerman 2006). Furthermore, the development of autonomous machinery may not interfere with the autonomy of individuals from the perspective of their continued yearning for utopia or dystopia (see Knights and Willmott 2002).

Robotics has already been applied, mostly in manufacturing, and its applications are constantly growing (Brynjolfsson and McAfee 2014). This growth in the use of robotics has brought about some speculation, suggesting a future social utopian order. Thus, Mason (2016) and Smicek and Williams (2015) presented a post-capitalist utopian world, in which autonomous robots would carry out people's work, and thus permitting the emergence of what has been termed as fully automated luxury communism (FALC). Under FALC, it was proposed that governments would pay some of the workers' social wages for a shorter week of work, financed by taxes. Such scenarios are supported by the estimate of Frey and Osborne (2013) that by 2050, some 47 percent of US jobs will be susceptible for automation, notably because of the growing use of robotics, along with wider computerization, AV adoption, cyberspatial activities, and more.

The possible future diminishing employment opportunities under a wide adoption of robots and AVs may relate mainly to jobs in manufacturing, as well as to transportation-related jobs, such as professional driving, driving teaching, and driving testing, whereas service jobs in numerous other employment branches may change only minimally, if at all. Moreover, robots and AVs will create new jobs and professions dealing with their maintenance and future development. Thus, the role of education for the ensuring of professional employment will increase. Still, though, the welfare of people who will not be able to study and work in technological areas may require governmental involvement.

\subsection{AUTOMATED SPATIAL MOBILITY}

Following our separate discussions so far on the three basic notions of spatial mobility, automation, and autonomy, accentuating their societal contexts, we will explore now more particularly the joint notion of automated spatial mobility, which is the emerging condition for the specific modes of mobility, which will be presented in the following chapters. By automated spatial mobilities we refer to the ability of people to move 
themselves or their information, as defined earlier in this chapter, through automated modes of mobility. Such automated mobility modes may be either non-automatic modes turned into automated ones, or they may have been automated ones originally. In some particular cases, automated spatial mobility may constitute a natural mechanism performed by the human body, as we will see in Chapter 2, but in most cases, automated spatial mobility involves the use of automated information and/or transportation technologies.

The incentives for the development of automated mobility media have been rather wide. Thus, the motivation for automated transmissions of information seems to be straightforward, since automation facilitates the synchronization and routing of calls, messages, and browsing. However, the motivations for the development of automation in transportation systems seem to be more varied. For example, the adoption of automatic transmission systems have brought about driving convenience and speed, whereas the introduction of traffic lights has been necessary for the management and safety of growing traffic. The motivation for the development of AVs has probably been more complex, as we will note in Chapter 6, involving the feasibility for less cars on the road, coupled with lower pollution levels, drastically fewer road accidents, greater convenience for car riders, and providing for additional work time for commuters while riding.

Automated spatial mobility consists of three cumulative pillars, so that the availability of automated mobility technologies will bring about their adoption and use by individuals, resulting in the emergence of intelligent mobility spaces shaped by automation technologies and their users (Figure 1.2). Even before the introduction of AVs, there have already been several automated mobility technologies in use by car drivers. These include by their historical order of introduction: traffic lights (1914); automatic transmission systems (1939); Global Positioning Systems (GPS)based navigation applications (1990); autonomous safety systems such as lane-keeping assist systems (2003), intelligent parking (2003), forward collision warning (2003), and autonomous emergency braking (2013). In the future, additional technologies will be introduced towards the introduction of AVs (see Table 6.1). Most of the currently existing automatic technologies for personal physical mobility are optional and are used by individual choice, except for those installed in cars as mandatory requirements by specific governments. Such mandatory status applies also to traffic lights, which constitute societal means for the regulation of traffic, so that abiding by them has been compulsory. In the more remote future, the very use of AVs may too become compulsory.

In some way, therefore, drivers may be differentiated by their preferences for the use of automated technologies in their driving. These 


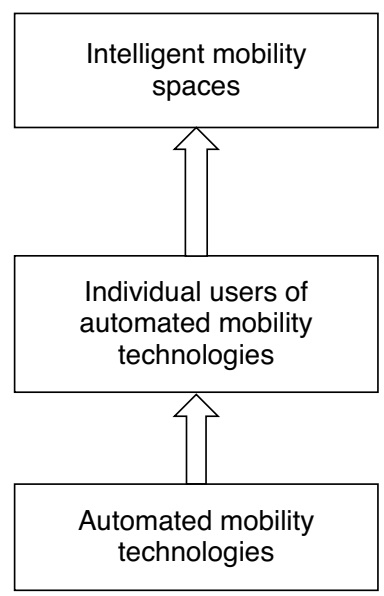

Figure 1.2 Pillars of automated mobility spaces

preferences may not only reflect personal habits, but also the price of automatic technologies, as well as the cost of their maintenance. A wellknown example is the higher purchase price and higher gas consumption pertaining to automatic transmission, to which we will relate in Chapter 2.

The future adoption of AVs will bring about highly intelligent mobility landscapes, to be discussed in Chapter 7. It will suffice here to note that the future intelligent traffic landscape, consisting of AVs as the only type of cars on the road, will present utmost smartness: all cars will be automatically driven; cars passing next to each other will be interconnected, and traffic lights will be able to communicate with approaching cars.

The current intelligent traffic landscapes involving automated mobility consist of hybrids of drivers and their cars (see Thrift 2004), differing from each other in their unique contribution to the cumulative traffic landscapes, a contribution which depends on their voluntary choice of automated systems that were installed in their cars and in the use of these automated systems while driving. Traffic constitutes, therefore, something that is more than numerous cars going from point A to point B. Several automated systems may contribute significantly to intelligent traffic landscapes. For example, automatic cars reach higher speeds faster following stops at road junctions, as compared to non-automatic ones; users of GPS-based navigation systems may contribute to the alleviation of traffic jams; and the more recently introduced automated safety systems may keep drivers in their proper lanes and facilitate emergency stopping. There are, obviously, cars on the road that are not equipped with any of these 
Table 1.2 Automation phases in transportation and communications

\begin{tabular}{|c|c|c|c|c|}
\hline Phase & Transportation & $\begin{array}{l}\text { Fixed-line } \\
\text { telephone }\end{array}$ & Mobile phone & Internet \\
\hline I & $\begin{array}{l}\text { Traffic } \\
\text { synchronization } \\
(1922)\end{array}$ & Routing (1878) & Routing (1979) & $\begin{array}{l}\text { Routing, } \\
\text { synchronization, } \\
\text { and autonomy } \\
\text { (1995) }\end{array}$ \\
\hline II & $\begin{array}{l}\text { Automatic } \\
\text { transmission } \\
\text { (1939) }\end{array}$ & $\begin{array}{l}\text { Synchronization } \\
\text { (1900) }\end{array}$ & $\begin{array}{l}\text { Synchronization } \\
\text { and autonomy } \\
\text { (1981) }\end{array}$ & \\
\hline III & $\begin{array}{l}\text { GPS-based } \\
\text { navigation } \\
(1990)\end{array}$ & $\begin{array}{l}\text { Autonomy } \\
\text { (1970) }\end{array}$ & & \\
\hline IV & $\begin{array}{l}\text { Autonomous } \\
\text { safety } \\
\text { technologies } \\
(2003-2013)\end{array}$ & & & \\
\hline V & $\begin{array}{l}\text { Autonomous } \\
\text { vehicles } \\
(2022-2025)\end{array}$ & & & \\
\hline
\end{tabular}

Source: See Tables 3.1, 5.1, 5.2, and 6.1.

automated systems, whereas others may be equipped with one or more of them.

The incorporation of automated systems in mobility devices has involved several phases towards the development of automated spatial mobilities, and these phases differ between transportation and information systems (Table 1.2). In transportation, we may identify five phases of automation from the driver's perspective, thus excluding automation processes introduced into mechanical car systems, such as the ignition. These five phases began with traffic synchronization via traffic lights (1922), followed by the introduction of automated transmission (1939), the facilitation of GPSbased routing/navigation (1990), the installation of autonomous safety systems (2003-2013), and culminated with the future adoption of AVs (2022-2025).

However, this sequence does not apply for the automation of virtual mobility modes. For the fixed-line telephone system, we may identify just three phases of automation, with routing being automated since the introduction of telephone services (1878). The later introduction of automated exchanges facilitated the synchronization of local calls (1900), instead 
of connections made manually by telephone exchange workers. The full synchronization of calls, implying autonomous operations of the fixedline telephone system, was achieved much later, when subscribers could for the first time perform international direct distance dialing (1970). For both cars and telephones, a long time passed between early automation, based on electric power, to advanced automation, based on the much later developed IT.

For the virtual mobility modes joining the fixed-line telephone later, at the IT age, there were even less automation phases, from the perspective of their introduction to subscribers. Thus, for mobile phones there were only two phases of automation, with just two years passing between them (1979-1981), and with regard to the Internet, which required automation from its outset for its very operation, for routing, traffic synchronization, and autonomous route choice, there was just a single phase (1995). We will discuss all of these phases in more detail separately for each mobility mode in Chapters 3-6.

It is further of interest to examine the possibly existing compatibility between the phasing of mobility automation, on the one hand, and the phasing of industrial development in general, on the other. Such a comparison is of special interest, since the upcoming years are viewed as ushering in a new phase of industrial development, whether it be a second one, the digital age following the industrial age (e.g. Brynjolfsson and McAfee 2014), or a fourth one (e.g. Schwab 2016). The notion of 'industry 4.0', proposed in 2011, assumes too an upcoming fourth industrial revolution, but within a rather specific context of proposals for German industrial production (VDI Nachrichten 2017). Davis (2016), based on Schwab (2016), proposed a detailed framework for the four industrial revolutions, and the four parallel ones for the automation of mobility systems have been added to them in Table 1.3.

As we noticed earlier in this chapter, as well as in Table 1.1, the beginning of the Industrial Revolution, or its first phase, which was based on steam power, involved early automation efforts in industrial production (e.g. complex textile pattern production by automatic looms), coupled with early automation efforts for steam engine operations (e.g. steam engine control). However, steamboats which were introduced early in the first industrial revolution, in the late 18th century, enjoyed the first introduction of automation, through the mechanical autopilots, much later, only in 1921-1922, following the introduction of autopilots for planes, in 1912-1914 (see Tables 4.3 and 4.4).

The second industrial revolution, based on electric power, brought about right from its outset, mobility automation efforts, notably for traffic control, the first of which was the electric automation block system for 
Table 1.3 The four industrial revolutions and the automation of mobility systems

\begin{tabular}{|c|c|c|c|c|}
\hline Revolution & $\begin{array}{l}\text { Year of } \\
\text { beginning }\end{array}$ & $\begin{array}{l}\text { General } \\
\text { industrial } \\
\text { innovations }\end{array}$ & $\begin{array}{l}\text { First automated } \\
\text { mobility } \\
\text { innovations }\end{array}$ & Year \\
\hline 1 st & 1784 & $\begin{array}{l}\text { Steam; } \\
\text { mechanical } \\
\text { production } \\
\text { equipment }\end{array}$ & $\begin{array}{l}\text { Early automation } \\
\text { (e.g. steam engine } \\
\text { control) }\end{array}$ & $\begin{array}{l}\text { Late } 18 \text { th } \\
\text { century }\end{array}$ \\
\hline 2nd & 1870 & $\begin{array}{l}\text { Division of } \\
\text { labor; oil-based } \\
\text { electric power; } \\
\text { oil-based internal } \\
\text { combustion } \\
\text { engine; mass } \\
\text { production }\end{array}$ & $\begin{array}{l}\text { Electric automatic } \\
\text { block system for } \\
\text { the controlling of } \\
\text { train traffic }\end{array}$ & 1869 \\
\hline $3 r d$ & 1969 & $\begin{array}{l}\text { Electricity-based } \\
\text { electronics; } \\
\text { IT; automated } \\
\text { production }\end{array}$ & $\begin{array}{l}\text { First electronic } \\
\text { telephone } \\
\text { switching system }\end{array}$ & 1965 \\
\hline 4 th & $?$ & $\begin{array}{l}\text { Electronics and } \\
\text { IT-based cyber- } \\
\text { physical systems }\end{array}$ & AVs & $2022-2025$ \\
\hline
\end{tabular}

Source: For the four industrial revolutions Davis 2016; for mobility systems see Tables $1.1 ; 3.2 ; 5.1 ; 6.1$.

the controlling of train traffic between pairs of signals (Table 3.2). The third industrial revolution, based on IT power, began at the same time when telephone services began their digitization process, whereas the upcoming fourth industrial revolution, based on an integration of artificial intelligence and IT ('cyber-physical systems'), will yield AVs as one of its first innovative devices. Thus, the beginning of each of the four general industrial revolutions is marked by the introduction, or an upgrading, of a mobility mode: steamboats (1st), trains (2nd), telephones (3rd), and AVs (4th).

The introduction of the automobile, the leading terrestrial transportation means, occurred within the second industrial revolution (1886), with the commercial introduction, 17 years earlier in 1869, of the internal combustion engine, which has been at the heart of car operations, being of special revolutionary importance, given its extensive impact, through 
its installation in cars and in the worlds of manufacturing, services, and mobility.

\subsection{CONCLUSION}

Automation in mobility will be exposed in this book, first for human natural movements, and then mainly for numerous mobility technologies. This variety of discussions will highlight the upcoming introduction of fully autonomous/automated cars from the wider perspective of automation in mobility, thus providing the context and early roots for the future AV revolution.

Spatial mobility has constituted the basic concept for this book, and displacement has constituted the essence of spatial mobility. Spatial mobility has further constituted an activity, an ability, and a structuring dimension for social life and social integration. Spatial mobility was further claimed to possess some hidden dimensions. As such, spatial mobility constitutes a meaningful condition, implying progress, freedom, opportunity, modernity, and speed, side by side with its provision for extensibility for moving individuals.

Our discussions of automated spatial mobilities in this book will refer to automation in daily physical and virtual mobilities, involving activities such as commuting, shopping, socializing, information search, banking, news updating, studies, business meetings, etc. These daily corporeal and virtual mobilities are typified through several features: they are two-way movements, which are frequently performed, and they constitute a major element of our daily routine lives.

Automation, or self-doing, and autonomy, or self-government for material processes, require, by their very nature, some non-human energy source for their very operation. In ancient times, this energy source was running water, replaced later by steam, during the first industrial revolution, by oil and electricity in the second, and by electronics in the third industrial revolution, as of the mid-20th century. The 21 st century is about to become the century of full autonomy for automated mechanical system operations, as compared to the 20th century, during which automation was introduced for specific mechanical system operations. The continued development and adoption of sophisticated robots, as well as the potential future introduction and adoption of AVs, may signify a realization of ancient human dreams for the development of self-operating machines.

Automated spatial mobility consists of three cumulative pillars, resulting from each other: automated mobility technologies; individual users of such automated technologies; and intelligent mobility spaces shaped 
by automation technologies and their users. These latter intelligent traffic landscapes of automated mobility consist of hybrids of drivers and their cars, differing from each other by their unique contribution to the cumulative traffic landscapes, which depends on their voluntary choice of automated systems to be installed in their cars.

Generally, the more people tend to move, the more automation is needed. This additional automation is required within cars in order to ensure safety when driving through increasingly congested traffic, and is further required for the coordination of the growing traffic. This relationship may also be true vice versa, so that the more automation there is in the operation of transportation systems, the greater the temptation by people to move, and to do so more conveniently.

The possible upcoming ultimate automated spatial mobility vis-à-vis the adoption of AVs will combine two ancient, and until quite recently rather separate, human desires. The first of these desires is the wish to move across space as much as possible, and the second is to develop and use automated, or self-operating, mechanisms. Hence, a full integration of these two desires may imply more movements by individuals, as well as the potential and as of yet unforeseen development of fully autonomous machines (i.e. robots) for spheres of life beyond those of transportation and manufacturing. 